\title{
Influence of decontamination on induction of arthritis in Lewis rats by cell wall fragments of Eubacterium aerofaciens. Arthropathic properties of indigenous anaerobic bacteria
}

\author{
Jeanette Kool, Anton J Severijnen, Ina S Klasen, Marjolein Y Gerrits-Boeye, \\ Maarten P Hazenberg
}

\begin{abstract}
Although the cause (or causes) of rheumatoid arthritis is unknown, many workers have suggested that microorganisms play a part. The intestinal flora in particular has been related to the development of joint inflammation. It has been shown previously that cell wall fragments of several anaerobic Gram positive intestinal bacteria of human origin are arthritogenic after a single intraperitoneal injection in Lewis rats. The part played by indigenous microflora in this model has now been studied by decontaminating Lewis rats before the injection of Eubacterium aerofaciens cell wall fragments. The pattern and severity of arthritis appeared to be comparable in decontaminated and control rats. The second goal of this work was to isolate arthritogenic bacteria from the autochthonous intestinal flora of rats. Only a limited number of bacteria showing a resemblance to arthritogenic strains from human intestinal flora (i.e. $E$ aerofaciens and Bifidobacterium adolescentis) could be isolated. These strains did not induce chronic arthritis after intraperitoneal injection. This may explain why spontaneous arthritis did not develop in Lewis rats.
\end{abstract}

Two models are used to determine the arthritogenicity of bacterial cell wall fragments or purified peptidoglycan polysaccharide complexes. The intraperitoneal route of injection (intraperitoneal model, first described for Streptococcus pyogenes by Cromartie et $a l^{1}$ ) is used for large bacterial fragments (i.e. $>10^{6}$ daltons). Subcutaneous injection (adjuvant arthritis model, first described for Mycobacterium tuberculosis by Pearson ${ }^{2}$ ) is useful for isolated peptidoglycan or peptidoglycan subunits and larger bacterial fragments. Using the intraperitoneal model we found that cell wall fragments from eubacterium and bifidobacterium species induced a severe and chronic arthritis in Lewis rats. Eubacterium cell wall fragments were also arthritogenic in the adjuvant model. Eubacterium and bifidobacterium species are Gram positive major residents of the human intestinal anaerobic flora occurring in numbers exceeding $10^{9}$ per gram of faeces. ${ }^{3-6}$ These findings add experimental evidence to the hypothesis that the bacterial load in the intestine plays a part in the aetiology of rheumatoid arthritis.

Spontaneous arthritis occurred in $0.5 \%$ of Sprague Dawley rats in an observation period of six months. ${ }^{7}$ The incidence increased to $6 \%$ after repeated total body irradiation. It is possible that the arthritis was triggered by bacterial products derived from intestinal flora. Irradiation enhances the uptake of whole bacteria, ${ }^{8}$ but probably also of bacterial products.

Information on the influence of the presence or absence of bacterial flora in arthritis models is limited. Pearson et al. ${ }^{9}$ showed that adjuvant arthritis could be induced in conventional and in germ-free Lobund rats. Others found that germ free Fisher rats were susceptible to the induction of arthritis in the adjuvant model using $M$ tuberculosis ${ }^{10-12}$ or the intraperitoneal model using streptococcal cell wall fragments, ${ }^{13}$ in contrast to their conventional littermates. Even less is known about the occurrence of arthopathic species among the indigenous bacteria of the intestine of rats. In our previous papers only bacterial strains isolated from human intestinal flora were studied.

In this study the direct influence of autochthonous rat flora on the induction of arthritis by Eubacterium aerofaciens cell wall fragments was investigated. First the effect of total intestinal decontamination on the development and severity of cell wall fragments induced arthritis was determined. Secondly, the intestinal flora of the rat was analysed for the presence of eubacterium and bifidobacterium species. Cell wall fragments of isolated strains were tested for arthritogenicity.

\section{Materials and methods}

INTESTINAL DECONTAMINATION

Male Lewis rats $(n=10)$ were decontaminated by adding $1 \mathrm{~g}$ ampicillin, $1 \mathrm{~g}$ neomycin, and $1 \mathrm{~g}$ polymyxin B per litre drinking water. Control rats (male, $n=5$ ) were given drinking water without antibiotics. The two groups were kept in sterilised cages and fed sterilised food. The composition of the intestinal flora was evaluated by microscopic examination of Gram stained faecal smears and by anaerobic and aerobic culturing of faecal dilutions. Decontamination was checked two weeks after the start of treatment with antibiotics and after six weeks, just before the administration of $E$ aerofaciens cell wall fragments. Antibiotics were continued during the whole experiment. At the end of the experiment decontamination was evaluated once more by faecal smears.

DIRECT FAECAL SMEARS

Samples of faeces were suspended in saline and spread on an object glass. After Gram staining 
the samples were examined for bacteria and yeasts. The detection limit of a direct smear was $10^{7}$ bacteria/g faeces wet weight.

ANAEROBIC CULTURE

Faeces of decontaminated and control rats were diluted and plated within one hour. Samples were suspended in the anaerobic diluent with a Stomacher Lab Blender (Colworth, London, UK). Serial ten fold dilutions were prepared from the suspensions. The anaerobic diluent contained (per litre distilled water): tryptone (Oxoid, London, UK), $5 \mathrm{~g}$; glucose, $5 \mathrm{~g}$; $\mathrm{K}_{2} \mathrm{HPO}_{4} \cdot 3 \mathrm{H}_{2} \mathrm{O}, 3 \mathrm{~g} ; \mathrm{KH}_{2} \mathrm{PO}_{4}, 0.5 \mathrm{~g} ; \mathrm{NaCl}$, $5 \mathrm{~g}$; L-cysteine hydrochloride (Sigma, MO, USA), $0.5 \mathrm{~g}$; and resazurin (BDH, Poole, UK), $0.002 \mathrm{~g}$. The $\mathrm{pH}$ was adjusted to $7 \cdot 2$. From the dilutions $0.2 \mathrm{ml}$ was plated in anaerobic flasks as described previously. ${ }^{14} \mathrm{~A}$ non-selective solid medium for anaerobes (Schaedler broth, Oxoid, with $2 \%$ agar, Difco) was used. Anaerobic conditions were verified by using the indicator resazurin $(0.0002 \%)$, which becomes pink at a redox potential greater than $-120 \mathrm{mV}$ at $\mathrm{pH}$ $7 \cdot 0 .^{15}$ After three days of incubation at $37^{\circ} \mathrm{C}$ the colonies were counted. The flora was determined according to methods used in previous work on flora composition. ${ }^{16}$ The microorganisms were separated into the following groups on the basis of morphology and Gram characteristics: Gram negative rods (bacteroides and fusobacterium) and Gram positive eubacterium or bifidobacterium species, cocci, and coccoid rods. More than $90 \%$ of the cultured organisms could be assigned to one of these groups.

\section{AEROBIC COUNTS}

Aerobic cultures were performed by plating the appropriate dilution of samples on to sheep blood agar plates; colonies were counted after 24 hours of incubation at $37^{\circ} \mathrm{C}$.

\section{ISOLATION AND IDENTIFICATION OF PROBABLE ARTHROPATHIC SPECIES}

Faeces from conventionally housed female Lewis rats $(n=2)$ were diluted and cultured as described under Ānaerobic culture. B̄acteria which were morphologically assigned as probable eubacterium or bifidobacterium species were subcultured. Pure cultures were identified according to the system of Holdeman et al. ${ }^{17}$

The carbohydrate fermentation capacity was determined under anaerobic conditions in peptone yeast extract medium with $0.05 \%$ $\mathrm{L}$-cysteine- $\mathrm{HCl}, 0.0002 \%$ resazurin, and $0.03 \%$ agar in sterilised $\left(121^{\circ} \mathrm{C}, 15\right.$ minutes) test tubes supplemented with $1 \%(w / v)$ of the following filter sterilised carbohydrates: amygdalin, arabinose, cellobiose, erythritol, esculin, fructose, glucose, glycogen, inositol, lactose, maltose, mannitol, mannose, melezitose, melibiose, raffinose, rhamnose, ribose, salicin, sorbitol, starch, sucrose, trehalose, or xylose. A culture $\mathrm{pH}<6.0$ after five days of incubation was labelled as positive.

The glucose fermentation products were determined by gas chromatography from five day incubates of the strains in peptone yeast extract broth with $1 \%$ glucose at $37^{\circ} \mathrm{C}$ under anaerobic conditions. ${ }^{18}$

PREPARATION OF BACTERIAL CELL WALL FRAGMENTS

Eubacterium aerofaciens (ATCC 25986) was cultured overnight at $37^{\circ} \mathrm{C}$ in Schaedler broth under strictly anaerobic conditions after inoculation with a log phase culture. The strains isolated from rat faeces were cultured under the same conditions on Todd Hewitt broth (Oxoid). Bacterial cell wall fragments were prepared as described by Cromartie et al. ${ }^{1}$ followed by the differential centrifugation procedure of Fox $e t$ $a l .{ }^{19}$ Briefly, cells were harvested, washed, and subsequently fragmented with glass beads in a Braun shaker (Melsungen, Germany). Cell walls were collected by $10000 \mathrm{~g}$ centrifugation, and treated with ribonuclease (Boehringer Mannheim, Germany) and trypsin (Sigma, USA), washed and sonicated (MSE, Crawley, UK) for 75 minutes. After the sedimentation of debris, the sonicated cell wall suspension was centrifuged at $10000 \mathrm{~g}$ for 30 minutes; the $10000 \mathrm{~g}$ supernatant was centrifuged twice at $100000 \mathrm{~g}$ for 60 minutes. Both $100000 \mathrm{~g}$ pellets were collected, resuspended in phosphate buffered saline and used for intraperitoneal injection after passage through a $0.45 \mu \mathrm{m}$ Millipore filter and subsequent control for sterility.

CHEMICAL ANALYSIS OF CELL WALL

PREPARATIONS

Muramic acid and rhamnose contents were determined as described by Hadzija ${ }^{20}$ and Dische and Shettles ${ }^{21}$ respectively. The total amount of carbohydrates was determined according to Dubois et al ${ }^{22}$ using galactose as standard.

INDUCTION OF ARTHRITIS

Six weeks after the start of the decontamination the decontaminated and control rats received an intraperitoneal injection of an aqueous suspension of $E$ aerofaciens cell wall fragments. The rats weighed $250-330 \mathrm{~g}$ at the time of injection.

Groups of five conventionally housed female Lewis rats (Herlan Sprague Dawley, Bicester, UK), weighing $110-185 \mathrm{~g}$, received an intraperitoneal injection of cell wall fragments of the bacteria isolated from rat faeces. All rats received a cell wall dose equivalent to $25 \mu \mathrm{g}$ of muramic acid per gram of body weight. The rats were observed for the development of paw inflammation at regular intervals for 60 days; the diameters of their wrists and ankles were measured with a vernier caliper at the distal end of the radius and at the malleoli respectively.

\section{STATISTICAL ANALYSIS}

The acute and chronic phase of the arthritis in decontaminated and control rats were compared as follows: for each rat in the decontaminated and control groups the mean increase in the sum 
of the paw diameters in the acute (day 1-15) and chronic (day 19-60) phases was calculated using the sum of the paw diameters of the same rat at day 0 as reference. The values for each phase found in the two groups were compared using the Mann Whitney U test.

\section{HISTOLOGY}

After 60 days, rats were killed by cardiac puncture bleeding under ether anaesthesia. Skinned paw joint specimens were fixed in $4 \%$ formalin, decalcified in 5\% (v/v) formic acid for five days and embedded in paraffin. Liver specimens were fixed in Bouin's fluid before embedding in paraffin. Sections were stained with haematoxylin and eosin.

\section{Results}

EVALUATION OF INTESTINAL DECONTAMINATION Gram stained faecal smears showed that the intestinal flora of decontaminated rats was significantly reduced after 14 days of drinking water with antibiotics. Culturing of faeces of intestinally decontaminated rats showed that anaerobic bacteria were no longer detectable (less than $10^{3} / \mathrm{g}$ faeces wet weight) and aerobes had decreased considerably (median $1.7 \times 10^{4}$ (range $<10^{3}-1 \cdot 1 \times 10^{6}$ ) bacteria/g faeces). In control rats $4.8 \times 10^{10}$ (range $3.5 \times 10^{10}$ $6.2 \times 10^{10}$ ) anaerobes and $9.7 \times 10^{7}$ (range $1.2 \times 10^{7}-1.8 \times 10^{8}$ ) aerobes/g faeces wet weight were found. After six weeks of decontamination five rats were selected for induction of arthritis, based on bacterial counts below the detection level of culturing $\left(10^{3} / \mathrm{g}\right.$ faeces). At the end of the experiment no or only small amounts of bacteria could be found in the faecal smears of these rats. All five rats had yeast in their faecal smears. At the time of death decontaminated rats had distended caeca filled with a watery content, a phenomenon characteristic of germ free rodents. ${ }^{923}$

The composition of the flora of the control rats did not change during the experiment.

\section{INDUCTION OF ARTHRITIS WITH AND WITHOUT} INTESTINAL DECONTAMINATION

After six weeks of intestinal decontamination the effect on arthritis induction by cell wall fragments of $E$ aerofaciens was tested. The results show that control rats with a normal flora (fig 1A) and decontaminated rats (fig 1B) developed an acute and a chronic arthritis.

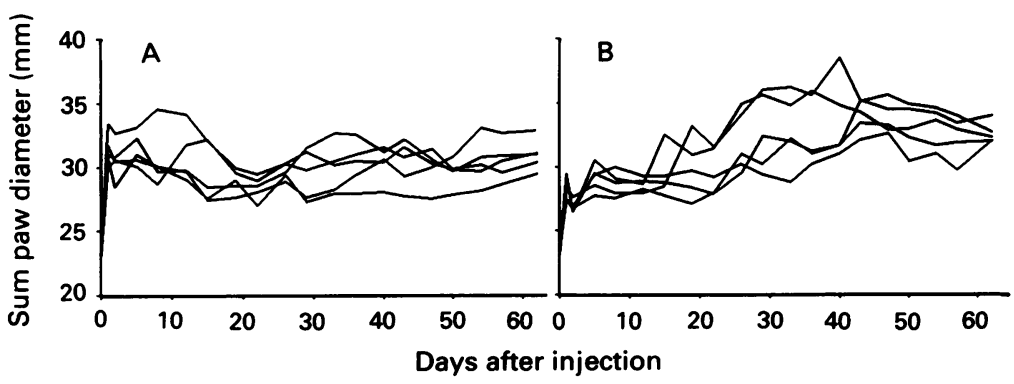

Figure 1 Induction of arthritis by $\mathrm{E}$ aerofaciens cell wall fragments ( $25 \mu \mathrm{g} \mathrm{MA} / \mathrm{g}$ body weight) in male Lewis rats. $(A)$ Control rats, $(B)$ decontaminated rats.

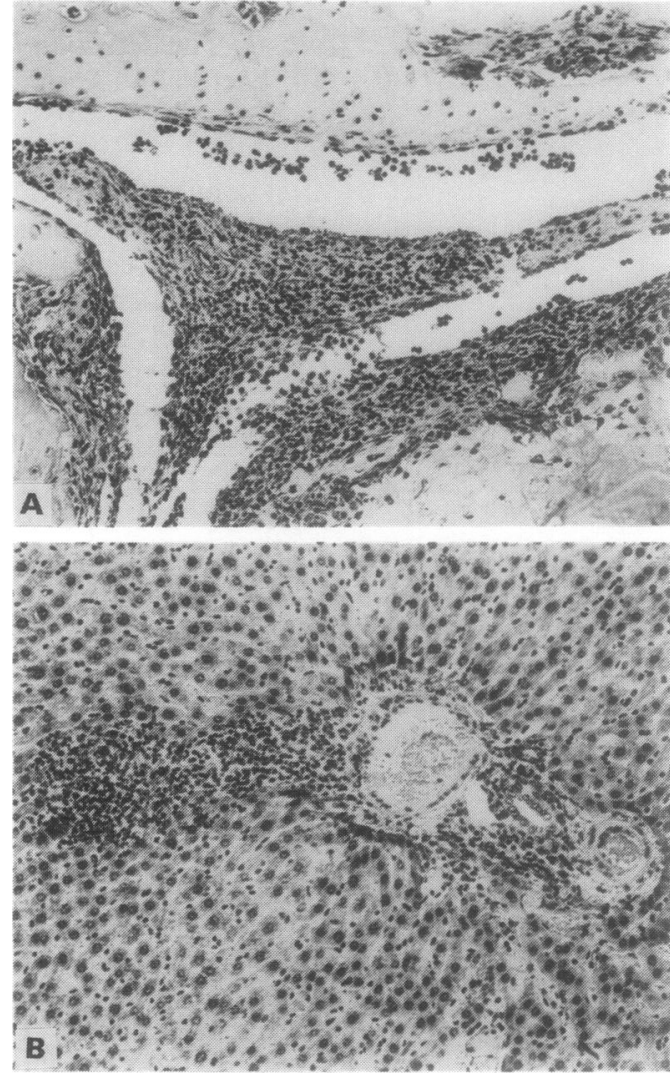

Figure 2 Histology of arthritic rat 60 days after injection with cell wall fragments of $\mathrm{E}$ aerofaciens. $(A)$ Section of an inflamed hind paw, with marginal erosions of the bone (left side), severely damaged cartilage (bottom right) and polymorphonuclear infiltrate in the joint space. (B) Section of a granulomatous liver, portal tract with histiocytic infiltrate extending into the parenchyme (haematoxylin and eosin staining).

Neither for the acute nor the chronic phase were statistically significant differences found between the two groups. The chronic arthritis was confirmed by histology at the end of the experiment. Figure 2A shows a severely damaged joint with infiltration of the joint cavity with polymorphonuclear cells and erosion of the cartilage and bone. Three rats (one of the control rats and two of the decontaminated rats) had macroscopic liver granulomas. Histologically the inflammation appeared to be localised mainly around the central veins and in the portal tracts, and consisted of a predominantly histiocytic infiltrate with sporadic lymphocytes (fig 2B).

PRESENCE OF POTENTIALLY ARTHROPATHIC BACTERIA IN THE RAT FLORA

After culturing the faeces of a conventional Lewis rat the flora was analysed in detail. Thirty five colonies of bacteria morphologically belonging to eubacterium, bifidobacterium, or related genera were further subcultured. A number of the pure cultures were similar, so 19 different strains were identified. Only one of the strains could be assigned to the genus eubacterium, none belonged to the genus bifidobacterium. The strains belonged to the genera peptostreptococcus (species: intermedius, productus, anaerobus, saccharolyticus), 


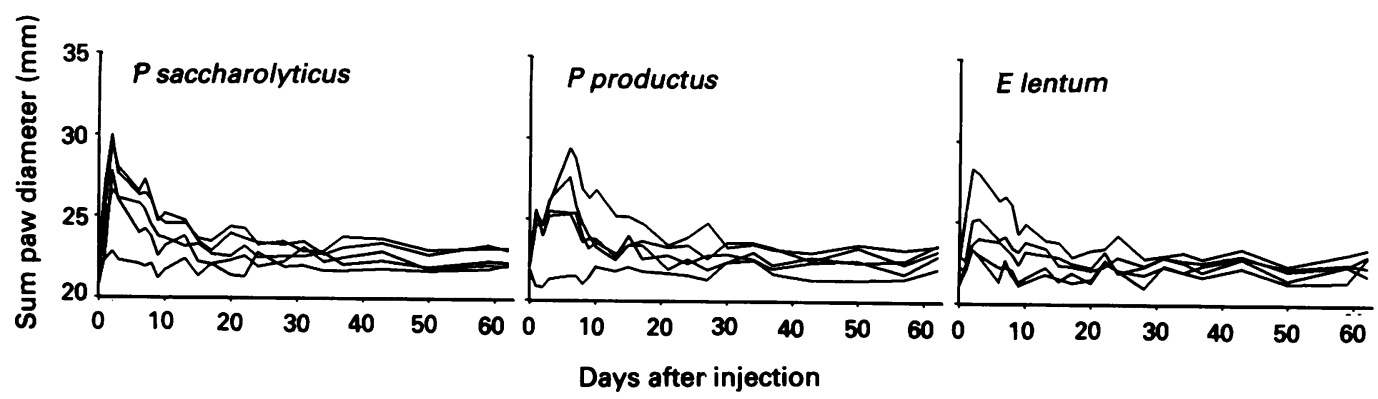

Figure 3 Induction of arthritis by cell wall fragments $(25 \mu \mathrm{g} \mathrm{MA} / \mathrm{g}$ body weight) from three stains isolated from rat faeces. $(A) \mathrm{P}$ saccharolyticus; $(B) \mathrm{P}$ productus, and $(C) \mathrm{E}$ lentum.

Chemical composition of cell wall fragments used for induction of arthritis. Contents are expressed as percentage of dry weight

\begin{tabular}{lllll}
\hline & \multicolumn{4}{c}{ Cell wall fragments } \\
\cline { 2 - 5 } & $E A$ & $P S$ & $P P$ & $E L$ \\
\hline Muramic acid & $15 \cdot 7$ & $20 \cdot 4$ & $16 \cdot 2$ & $17 \cdot 5$ \\
Rhamnose & $23 \cdot 4$ & $41 \cdot 3$ & $30 \cdot 0$ & $43 \cdot 6$ \\
Total carbohydrates & $64 \cdot 4$ & $74 \cdot 3$ & $60 \cdot 1$ & $76 \cdot 3$ \\
\hline "Cell wall fragments from $E$ aerofaciens (EA) and from rat \\
strains $P$ saccharolyticus (PS), $P$ productus (PP), and $E$ lentum \\
(EL).
\end{tabular}

peptococcus (species: magnus, constellatus), eubacterium (species: lentum), and ruminococcus (species: albus).

On basis of morphology and the production of volatile acids and ethanol, strain R11 ( $P$ saccharolyticus), R12 ( $P$ productus), and R19 ( $E$ lentum) showed the closest resemblance to the arthropathic $E$ aerofaciens.

ARTHRITIS INDUCTION BY CELL WALL FRAGMENTS FROM THREE RAT STRAINS OF BACTERIA

Cell wall fragments from the rat strains $P$ saccharolyticus, $P$ productus, and $E$ lentum were tested for the induction of arthritis. The table gives the muramic acid, rhamnose, and total carbohydrate contents of the cell wall fragments of the three rat strains compared with $E$ aerofaciens cell wall fragments. Figure 3 shows the results of the induction of arthritis; the cell wall fragments of the three rat strains of bacteria induced a self limiting acute joint inflammation. Histological examination 60 days after the injection of cell wall fragments showed no signs of active or previous inflammation.

\section{Discussion}

The supply of ampicillin, a moderately absorbable antibiotic, by mouth, in combination with neomycin and polymyxin B both non-absorbable, almost completely eliminated the intestinal flora of rats. After six weeks of intestinal decontamination, predominantly yeasts and, in some rats, a limited number of Gram negative rods were present. These persisted until the end of the experiment. The occurrence of yeasts after intestinal decontamination has been observed before. ${ }^{24}$ Some features of germ free rats, such as mild diarrhoea, an enlarged caecum ${ }^{93}$ and the absence of intestinal flora derived enzymes have also been described for intestinally decontaminated rats. ${ }^{24} 26 \mathrm{We}$ also found diarrhoea and caecal distension in decontaminated rats.
Elimination of the largest pool of bacterial antigens did not alter the susceptibility for arthritis induced by $E$ aerofaciens cell wall fragments. Conventional and intestinally decontaminated rats developed a comparable acute and chronic arthritis. Neither the severity nor the pattern of arthritis was influenced by the presence or absence of the indigenous flora. The amount of cell wall fragments (approximately $20 \mathrm{mg} / \mathrm{rat}$ ) injected contained sufficient peptidoglycan to start and maintain a joint inflammation for at least 60 days. These findings are consistent with the results of Pearson et al. ${ }^{9}$ who found in the adjuvant arthritis model that germ free Lobund rats were as susceptible to the induction of $M$ tuberculosis as conventional animals, although the onset of arthritis was slightly delayed. In these experiments an even smaller amount of bacterial material was sufficient $(0.5 \mathrm{mg} / \mathrm{rat})$. An influx of peptidoglycan from the gastrointestinal tract is obviously not necessary for the development or continuation of arthritis.

Others have also found that the germ free status does not prevent arthritis. On the contrary, rat strains normally not or hardly susceptible developed more often and more severe arthritis when they were germ free. This is shown both in the adjuvant arthritis model ${ }^{10}$ and in the streptococcal model. ${ }^{13}$ The experiments of Kohashi et al ${ }^{11} 12$ indicate a protective role for Gram negative bacteria: Escherichia coli or bacteroides monocontaminated Fisher rats developed a less severe arthritis than germ free Fisher rats. Gram positive lactobacilli increased the susceptibility to arthritis of germ free Fisher rats. This effect was abolished by the simultaneous administration of $E$ coli. The lipopolysaccharides of gram negative bacteria are said to protect against arthritis, ${ }^{27}$ whereas bacterial peptidoglycan is capable of inducing or aggravating the disease. The protective effect of the intestinal flora in rats which are not susceptible to arthritis has until now only been investigated in selectively contaminated germ free rats. It would be interesting to observe the effect of intestinal decontamination on induction of arthritis in such rats. A continuing lack of susceptibility after intestinal decontamination might mean that rats become tolerant to arthritis by their intestinal flora in the neonatal state.

It is remarkable that we never observed a spontaneous arthritis in Lewis rats, although they are very susceptible to the induction of 
arthritis both in the adjuvant model and in the intraperitoneal model. This is in contrast with the work of Trentham $e t a l,{ }^{7}$ who described a spontaneous development of arthritis in $0.5 \%$ of female Sprague Dawley rats. The incidence increased to $6 \%$ after total body irradiation with 17 fractions of $2 \mathrm{~Gy}$. Translocation of bacteria from the intestine to the mesenterial lymph nodes has been described after irradiation for mice, ${ }^{8}$ and after thermal injury ${ }^{28}$ or haemorrhagic shock ${ }^{29}$ for rats. Without the presence of arthritogenic bacteria in the intestine, however, it is unlikely that arthritis will occur in either conventional or irradiated animals.

In our previous studies we have shown the arthritogenicity of several anaerobic bacteria of the human intestinal flora in Lewis rats. Eubacterium and bifidobacterium species especially were able to induce a severe chronic arthritis. We have tried to isolate potentially arthritogenic bacteria (i.e. eubacterium and bifidobacterium species) from the indigenous flora of Lewis rats by a method used for the isolation of arthropathic $E$ aerofaciens strains from the intestinal flora of healthy subjects and patients with rheumatoid arthritis. Although 19 strains resembled eubacterium or bifidobacterium species morphologically, however, only one could be identified as belonging to the genus eubacterium ( $E$ lentum). This result is in agreement with descriptions of the intestinal flora of conventional rats by several workers. Although Raibaud et al ${ }^{30}$ found bifidobacterium and eubacterium species among the dominant intestinal flora of conventional rats occurring in numbers between $10^{7}$ and $10^{10}$, more recent studies give lower numbers of these genera. Rowland ${ }^{31}$ found less than $0.8 \%$ bifidobacterium in the faeces of Sprague Dawley rats, no eubacterium species were isolated. In caeca of Wistar rats Morishita and Miyaki ${ }^{32}$ found a maximum of $10^{6}$ bifidobacteria at the age of four to nine weeks. Younger and older rats had lower numbers of bifidobacteria. In this study eubacteria were not considered as a separate group, but were counted as catenabacteria together with anaerobic lactobacilli, preventing any conclusions about the numbers of this genus.

In addition to $E$ lentum, two more strains isolated from rat flora were selected for the induction of arthritis. Although we have chosen the strains that most resembled the arthropathic $E$ aerofaciens, none of them was able to induce a chronic arthritis. All three strains gave only an acute arthritis. This has been described before for $P$ productus, but $E$ lentum was capable of inducing a chronic arthritis after the initial acute joint inflammation in earlier experiments, using ATCC strains. ${ }^{5}$

The failure to induce arthritis cannot be explained by a low muramic acid content because this was as high as in $E$ aerofaciens cell wall fragments. Nor can it be explained by the rhamnose content, which was even higher than in $E$ aerofaciens cell wall fragments. Other, unknown, characteristics are to be held responsible for the difference in arthritogenicity between $E$ aerofaciens and the three rat strains of bacteria.
Although we have tested only a limited number of bacterial strains from the rat flora, we believe that arthropathic bacteria are not abundant in the intestinal tract of Lewis rats. This absence of triggering peptidoglycan may explain why we never found a spontaneous arthritis in susceptible Lewis rats, although this rat strain is extremely susceptible to the induction of arthritis by cell wall fragments of intestinal anaerobic bacteria of human origin.

We thank $\mathrm{Mr} \mathrm{T}$ van Os for his skilful photographic assistance and Mrs $\mathrm{H}$ J Elsenbroek-de Jager for secretarial help. This study was financially supported by the Nationaal Reumafonds (Dutch Rheumatism Foundation)

1 Cromartie W J, Craddock J G, Schwab J H, Anderle S K, Yang $\mathrm{C} \mathrm{H}$. Arthritis in rats after systemic injection of streptococcal cells or cell walls. $\mathcal{F}$ Exp Med 1977; 146: 1585-602.

2 Pearson C M. Development of arthritis, peri-arthritis and periostitis in rats given adjuvants. Proc Soc Exp Biol Med 1956; 91: 95-101.

3 Severijnen A J, Hazenberg M P, Van de Merwe J P. Induction of chronic arthritis in rats by cell wall fragments of anaerobic coccoid rods isolated from the faecal flora of of anaerobic coccoid rods isolated from the faecal flora of
patients with Crohn's disease. Digestion 1988; 39: 118-25.

patients with Crohn's disease. Digestion 1988; 39: 118-25.
4 Severijnen A J, Van Kleef R, Hazenberg M P, Van de Merwe $J$ J P. Cell wall fragments from major residents of the
. $J$ P. Cell wall fragments from major residents of the f R Reumatol 1989; 16: 1061-8.

5 Severijnen A J, Van Kleef R, Hazenberg M P, Van de Merwe $J$ P. Chronic arthritis induced in rats by cell wall fragments of Eubacterium species from the human intestinal flora. Infect Immun 1990; 58: 523-8.

6 Severijnen A J, Kool J, Swaak A J G, Hazenberg M P Intestinal flora of patients with rheumatoid arthritis. Induction of chronic arthritis in rats by cell wall fragments from isolated Eubacterium aerofaciens strains. $\mathrm{Br} \mathcal{F} R$ heumatol 1990; 29: 433-9.

7 Trentham D E, Brahn E, Williams W, McCune W J, Belli $\mathrm{J}$ E. Connective tissue disease can develop in rats either spontaneously or after total lymphoid irradiation. $\mathcal{F}$ Rheu matol 1984; 11: 410-2.

8 Brook L, MacVittie T J, Walker R I. Recovery of aerobic and anaerobic bacteria from irradiated mice. Infect Immun 1984 46: 270 - 1 .

9 Pearson C M, Wood F D, McDaniel E G, Daft F S. Adjuvant arthritis in germfree rats. Proc Soc Exp Biol Med 1963; 112 91-3.

10 Kohashi O, Kuwata J, Umehara K, Umehara F, Takahash T, Ozawa A. Susceptibility to adjuvant arthritis among germfree, specific-pathogen-free and conventional rats. Infect Immun 1979; 26: 791-4.

11 Kohashi O, Kohashi Y, Takahashi T, Ozawa A, Shigemats N. Reverse effect of Gram-positive bacteria vs. Gramnegative bacteria on adjuvant induced arthritis in germfree rats. Microbiol Immunol 1985; 29: 487-97.

12 Kohashi O, Kohashi Y, Takahashi T, Ozawa A, Shigematsu N. Suppressive effect of Escherichia coli on adjuvan N. Suppressive effect of Escherichia coli on adjuvant
induced arthritis in germfree rats. Arthritis Rheum 1986; 29: $547-53$.

13 Van den Broek M F, Van Bruggen M C J, Van de Putte L B A, Hazenberg M P, Van den Berg W B. Gut flora L B A, Hazenberg M P, Van den Berg W B. Gut flora
induces and maintains resistance against streptococcal cell induces and maintains resistance against streptococcal cell
wall-induced arthritis in rats. Arthritis Rheum 1990; 33: wall-ind

14 Wensinck F, Ruseler-van Embden J G H. The intestinal flora of colonization-resistant mice. F Hyg 1971; 69: 413-21.

15 Ruseler-van Embden J G H, Both-Patoir HC. The applicability of redox-indicator dyes in strongly reduced media; thei effect on the human fecal flora. FEMS Microbiol Lett 1985, 28: $341-5$.

16 Hazenberg M P, Bakker M, Verschoor-Burggraaf A. Effects of the human intestinal flora on germ free mice, $\mathcal{J} A p p l$ Bacteriol 1981; 50: 95-106.

17 Holdeman L V, Cato E P, Moore W E C. Anaerobic laboratory manual. 4th ed. Blacksburg: Anaerobe Laboratory,
Virginia Polytechnic Institute and State University, 1977.

18 Ruseler-van Embden J G H, Both-Patoir H C. Anaerobic Gram-negative faecal flora in patients with Crohn's disease and healthy subjects. Antomie van Leeuwenhoek 1983; 49: and health.

19 Fox A, Brown R R, Anderle S K, et al. Arthropathic properties related to the molecular weight of peptidoglycanpolysaccharide polymers of

$20 \mathrm{Hadzija} \mathrm{O}$. A simple method for the quantitative determination of muramic acid. Anal Biochem 1974; 60: 512-7.

21 Dische Z, Shettles L B. A specific color reaction of methylpentose and a spectrophotometric micromethod for their determination. $\mathcal{f}$ Biol Chem 1948; 175: 595-603.

22 Dubois M, Gilles K A, Hamilton J K, Rebers P A, Smith F Colorimetric method for determination of sugars and related substances. Anal Chem 1956; 28: 350-6. 
23 Thompson G R, Trexler P C. Gastrointestinal structure and unction in germ-free or gnotobiotic animals. Gut 1971; 12 $230-5$.

24 Carratelli C R, Nuzzo I, Caldiero E. Changes in the intestinal microflora of rats fed different diets or antibiotics. Micro ecology and Therapy 1989; 18: 127-32.

25 De Herder W W, Hazenberg M P, Pennock-Schröder A M Oosterlaken A C, Rutgers M, Visser T J. On the enterohepatic circulation of triiodothyronine in rats: importance of the intestinal microflora. Life Sci 1989; 45: 849-56.

26 Hazenberg M P, De Herder W W, Visser T J. Hydrolysis of iodothyronine conjugates by intestinal bacteria. FEMS iodothyronine conjugates by intestinal bacteria. FEMS

7 Wood F D, Pearson C M. Protection of rats against adjuvan arthritis by bacterial lipopolysaccharides. Science 1962 137: $544-5$

28 Maejima K, Deitch E A, Berg R D. Bacterial translocation from the gastrointestinal tracts of rats receiving thermal injury. Infect Immun 1984; 43: 6-10.

29 Deitch E A, Morrison J, Berg R, Specian R D. Effect of hemorrhagic shock on bacterial translocation, intestinal morphology, and intestinal permeability in conventional and antibiotic-decontaminated rats. Crit Care Med 1990; 18: 529-36.

30 Raibaud P, Dickinson A B, Sacquet E, Charlier H, Mocquot G. La microflore du tube digestif du rat. II-Denoml'intestin de rats conventionnels. Variations quantitativesindividuelles et en fonction de l'age. Ann Inst Pasteur 1966; 110: 861-76.

31 Rowland J R. In vitro models of the mammalian caecum and colon. In: Hill M J, ed. Models of anaerobic infection. Dordrecht, The Netherlands: Nijhoff, 1984: 120-2.

32 Morishita Y, Miyaki K. Effects of age and starvation on the gastrointestinal microflora and the heat resistance of fecal bacteria in rats. Microbiol Immunol 1979; 23: 455-70. 